\title{
Men's experiences of giving and taking social support after their wife's spinal cord injury
}

\author{
GUNILLA ISAKSSON ${ }^{1}$, STAFFAN JOSEPHSSON ${ }^{2}$, JAN LEXELL ${ }^{1,3,4}$ \& LISA SKÄR ${ }^{1}$ \\ ${ }^{1}$ Department of Health Sciences, Luleå University of Technology, Luleå, Sweden, ${ }^{2}$ Neurobiology, Care Sciences and Society, \\ Division of Occupational Therapy, Karolinska Institute, Huddinge, Sweden, ${ }^{3}$ Department of Rehabilitation, Lund University \\ Hospital, Lund, Sweden, ${ }^{4}$ Department of Clinical Sciences Lund, Division of Rehabilitation Medicine, Lund University, \\ Lund, Sweden
}

\begin{abstract}
The aim of this study was to gain an understanding of how men living with women with spinal cord injury (SCI) experienced and acted when they were giving and taking social support to and from their wives and other persons in their social network. Another aim was to give some possible explanations of the complex process of change that they went through. Data were collected through in-depth interviews with four men and field notes. To describe the men's subjective experiences and the process of change, a narrative approach inspired by Polkinghorne was used. The analyses resulted in one story that included the four men's experiences and action. The story showed that when the men went through a process of change, they used and needed both emotional and practical support to handle their new life situation. Furthermore, the men's experiences and action against social support changed over time. This indicated that, through narratives from spouses, professionals within rehabilitation could understand the process of change they went through after their partner's sudden injury, and support them to find strategies to handle their changed life situation. To give some possible explanations for the men's experiences and action during the process of change, the findings are discussed in relation to theories concerning adaptation and coping.
\end{abstract}

Key words: Adaptation, coping, occupational therapy, rehabilitation, social support, spouses

\section{Introduction}

Social support is important in the rehabilitation of persons with sudden injury or disease and for their participation in daily occupations (1-7). Social support is used as an umbrella term that encompasses various types of support and is conceptualized from two perspectives: that of the support provider and that of the recipient (8). It has been shown that spouses play an important role providing social support in changed life situations $(6,9)$. It is also known that it is difficult for spouses to handle this new situation (10-12). Even though occupational therapists know that spouses are important for the rehabilitation, our knowledge is limited on how they manage to support their partners and how spouses' changed life situation affects their daily life.

A spinal cord injury (SCI) can cause sudden paralysis and have major medical, psychological, and social consequences for the person concerned. These consequences affect the person's roles, relations, and occupations, and many aspects of family life (13). How persons adapt and find meaning in daily life often depends on their relationships that are built on earlier social constructions, where spouses are particularly important (14-16). Social support from spouses is therefore an important factor for successful rehabilitation of persons with disabilities and their adaptation to a changed life situation $(2,3,17,18)$. Our earlier studies $(1,6,7)$ have shown that partners are important for women with SCI as they provide motivation and ability for the women to participate in daily occupations. Several earlier studies have shown that this new situation is very complex for spouses (19-22). Spouses are often willing to take this new role of primary caregiver and provide support at the same time as they live

Correspondence: Gunilla Isaksson, MSc OT PhD, Department of Health Sciences, Luleå University of Technology, 97187 Luleå, Sweden. Tel: +46 920 49 38 53; E-mail: gunilla.isaksson@1tu.se 
with fear and frustration since they also undergo an adjustment similar to that of their disabled partners $(12,20)$. Spouses are also expected to provide support to their partners so they can come to terms with their disability (19). This can result in high cost to spouses' own personal lives due to less time for rest and leisure activities $(9,12)$. Furthermore, this caregiving burden, as a result of their partner's dependency, can be a main source of stress $(20,21)$. Spouses also seek some degree of balance in their new and often confusing situation, as they lack the appropriate knowledge to assume this role $(8,12)$. Several studies indicate that spouses are not offered appropriate support, such as information and guidance, by professionals in rehabilitation, so that they can adapt to the changed life situation and support their disabled partners $(10-12,22)$. To handle the new role as caregivers, spouses search for support from family and friends (12). These studies indicate that spouses of persons with SCI also reach a turning point where they have to adapt to changed habits and roles in daily life. During this process, they are expected to support their partners at the same time as they are in need of support from family members, friends, and professionals within rehabilitation.

Theories about adaptation have often been used to explain the process of change that persons go through after a major turning point in life. Adaptation can be described as a normal dynamic process involving the person, the environment, and their interaction (14,23-25). The process is cumulative and has to be seen in the context of the person's lifetime experiences, as every person must alter some of his or her established behaviour to adapt to the new situation. Coping theory is also used since coping is a key concept for the theory in the research on adaptation (26). This theory involves specific reactions to stressful situations and changes over time in accordance with the context in which it occurs. The coping process consists of an evaluation of the personal significance of an event (primary appraisal) and of the available coping options (secondary appraisal), followed by cognitive or behavioural reactions (coping strategies) $(19,26)$. Thus, coping can be viewed as a process that affects the outcome of adaptation (27). There is also a mutual relationship between coping and social support in the process of adaptation (19), since social support and advice provided by family and friends can be regarded as a coping resource (28). According to McColl (17), coping is initiated by the individual and social support by others, and social support is most effective when it complements, rather then supplements, personal coping. However, it can be argued that these theories focus on traits in the process of change rather than on the dynamics of the process. From an occupational therapy perspective, it is of interest to understand the persons' action to find meaning in their daily occupations. This can be done through narratives, which are individuals' way of interpreting and making meaning from experiences to explore possible understanding rather than fixed representations (29). Narratives can therefore be used as a method to preserve the complexity of human action with its interrelationship of temporal sequence, human motivation, change happenings, and changed interpersonal and environmental contexts (30).

Taken together, the description above indicates that we need to increase our knowledge within rehabilitation regarding the complex process of change that spouses go through after their partners have had an SCI. Furthermore, it is of interest to use theories on adaptation and coping to understand this changed life situation. The aim of this study was therefore to get an understanding of how men living with women with SCI experienced and acted when they were giving and taking social support to and from their wives and other persons in their social network. Another aim was to give some possible explanations for the complex process of change that the men went through.

\section{Material and method}

Design

To understand the men's experiences and the process of changes, we have used a narrative approach inspired by Polkinghorne (30). Data employed in this narrative approach, which Polkinghorne called a "Narrative analysis of eventful data", are diachronic descriptions of events, i.e. data containing temporal information when events occurred, their effects, and relationships between them. The purpose of the analysis is to describe and explain dynamics and processes through stories as the outcome of the research. The analysis should result in an explanation that is retrospective, where past events have been linked together towards a final outcome. The creation of the text involves a to-andfro movement from parts to whole to reach a level of comprehension which results in a finished text (31). The final narrative must fit the data while at the same time bringing an order and meaningfulness that is not apparent in the data themselves (30).

\section{Participants}

The participants were selected through purposeful sampling (32), based on our earlier studies $(1,6,7)$ which have shown that partners are of importance during the rehabilitation process. Participants in this 
study were therefore selected according to the following criteria: (a) they were married to/cohabitants of women with SCI who have participated in our earlier studies, and (b) they have the consent of women to participate. Initially a letter was sent to 10 women who at the time of the study were married/cohabitants and had participated in our earlier studies. They were informed that the results of these studies have shown the importance of their husbands/cohabitants in the rehabilitation process. The women were asked to give an attached letter to their men with information about the aim of the present study and a request to participate. The men were also informed that they could withdraw from the study at any time. When the men decided to participate, they returned written informed consent to the first author. Four of the 10 men decided to participate. The Research Ethics Committee of Lund University, Sweden approved the study.

A short description follows of the participants Carl, Peter, Steve, Michael (fictitious name), and their wives:

- Carl and his wife are around 50 and were both in an accident a couple of years ago. $\mathrm{He}$ was uninjured but his wife had a cervical SCI. They live in a house and have grown-up children. Before the accident, they spent a lot of time together in different leisure activities. After the accident, his wife needed a lot of support both from him and from professionals to manage her daily life.

- Peter is around 40, and met his wife some years after she had her thoracic SCI in an accident. She uses a wheelchair and despite her disability she can manage her daily life almost by herself. They live in a house and have dogs and cats.

- Steve is around 60 and had experiences of his wife's earlier illness before she received the SCI. They live in a house and have grown-up children. His wife has regained the capacity to walk shorter distances with walking sticks.

- Michael is around 40 and his wife had a thoracic SCI following an accident several years ago. She uses a wheelchair but she can manage her daily life almost by herself. They live in a house and have small children.

\section{Data collection}

The data were collected by the first author through in-depth interviews and field notes during the spring of 2006. The men were interviewed separately in a neutral room at a rehabilitation clinic. All questions were open-ended, aiming to capture the participants' own stories (33) about events, where they had interacted in giving and taking support with their wives and other people in their social network. They were also asked to narrate how they experienced and acted in these events. Follow-up questions were asked to ensure that the time perspective was covered to encourage the process of changes. The open-ended interviews gave rich information and became rather long (1-1.5 hours). These interviews and the field-notes raised some new questions about how the men had acted in some of the events they narrated. This led to follow-up interviews with all the men which were made over the phone and lasted about 30 minutes. All interviews were tape-recorded and transcribed verbatim.

\section{Data analysis}

The analyses were guided by Polkinghorne's (30) description of "Narrative analysis of eventful data". The first step was to obtain an overall sense of the data through repeated reading of the transcribed interviews by the first and the last author. As a second step the first author started to search for events in each man's story that matched the aim of the study and arranged them over time in story-lines. The four different story-lines were then compared with each other. Similar events were put together and plots were created. At this step, we found that the plots contained complexities and differences, for example, complexities in events in relation to how the men experienced the situation immediately after the women's injury. To continue the analyses, we used a process called "Narrative smoothing" (34), a process in which elements in data that will become part of the results are included because not all data are needed to tell the story. In this step, we used some of the plots to shape one story that could give a possible explanation of the aim of the study, and thus not all plots were used. The first, second, and last author then compared the story with plots not used and discussed whether these plots could expand the understanding of the complexity in the men's changed life situation. The first author, thereafter, continued the analyses to get a deeper understanding of the complexities that unfold in the plots by a toand-fro movement between the emerging story and plots not included in this story. Through this to-andfro movement, all plots were finally included in the story, giving an understanding of an unfolding, complex and dynamic process of change. This final story gave an explanation of the men's experiences and action over time in relation to social support. The understanding of the process of change that the men experienced developed through the to-and-fro movement between the events, the plots, and the story, and was a process similar to a hermeneutic 
circle (31). The first author then had a final discussion with the other authors to bring order and meaningfulness to the result and to ensure that the final findings gave an understanding to the dynamics and complexity in the story. The function of a narrative analysis is to answer how and why a particular outcome came about (30). Through the final story, based on the analyses of all data as outlined above, the results express the complexity of the men's experiences and actions during the process of change.

\section{Results}

The results are presented through one story that includes Carl, Peter, Steve, and Michael's experiences and actions when they were giving and taking support to and from their wives and other persons in their social network after the SCI. This story is described through the men's different experiences of social support and the unfolding dynamic complexity of how they adapted over time to find strategies to handle their changed life situation will be presented. The men's experiences and actions when they were giving and taking social support will be presented through one common story-To handle a changed life situation - with headings that point out the time perspective.

\section{To handle a changed life situation}

"Deepest within you, you only want to forget". The women's SCI was a shocking experience and a turning point in life for both the women and the men living with their wife at the time. Right after the injury the men found it hard to believe what had happened and to understand how the SCI would influence their common life. They experienced that the women received both emotional and practical support from rehabilitation professionals to adapt to their disability and the consequences of the SCI. The men themselves, on the other hand, received no emotional support from professionals for their feelings of anxiety or helplessness. Nor did they receive any information about the SCI and what consequences it could lead to, even though they had to adapt to a changed life situation. The men therefore developed different strategies to handle this new situation. It seemed as if men with previous experiences of life crises were able to handle this new situation in a better way emotionally than the men without such experiences. This gave them better strategies to handle their emotional thoughts and feelings by themselves and the changed life situation together with their wife. One man expressed it like this:

I do not know if you get a little, you know resistant; I believe that you will not be as shocked as other people who never have been affected by anything.

Men with no previous experiences of a sudden disease found it difficult to handle the changed life situation by themselves and, therefore, searched for support from family members and friends instead of support from professionals within rehabilitation. Despite the fact that these men experienced needing emotional support from professionals soon after the injury, they declined the emotional support from professionals that they were offered some time after the women's SCI. The reason was that it was difficult to narrate details of feelings and thoughts with professionals. One man gave this explanation:

I guess it was the feeling that you have to talk about everything from the beginning again when, deepest within you, you only want to forget. When you have this feeling you don't find it particularly encouraging to start all over again.

As can be seen from the example above, emotional support from family members and friends, such as listening and sharing the men's experiences, was important for the men as well as complex to handle. Still, they felt that these persons were there for them and had time to listen to them, especially soon after the women's SCI. Through this emotional support, it became easier for the men to support their wives in the adaptation process towards a changed life situation. The men also asked for and got practical support from family members and friends, for example through environmental changes to make modifications in the home environment. These modifications were important for the women's ability to participate in occupations at home. However, soon after the women's injury, the men also experienced feeling that family members and friends were a burden for them. One reason was that these individuals used the men as links to the women. The men felt that it was difficult to be this link, partly because they felt unable to handle the new situation. They were anxious about their wife's condition and therefore found it difficult to talk about it. Despite their feeling that family members and friends need to have them as a link was a burden, they still continued to answer questions about their wives. Nevertheless, they experienced that family members and friends 
acting in this way were not giving them the emotional support they needed.

"It was a crash in our life". It was not until the women came home after their rehabilitation that the men became aware of how their life situation had changed, with new roles and habits in their life. Up to this point, the men had focused on the women's rehabilitation and not on how their own life would be when the women came home. The men felt that they were not prepared for this new situation and that this affected them strongly. One man described the return of his wife like this:

It was a crash in our life, at that moment reality came into our life and I know that it was a crash and it was like, I felt like.... I remember one situation when the technician was there to remodel our house and at that moment we lost our strength and we just cried. I remember that there were four technicians, I remember this as a tragicomic situation, but it was terrible of course.

The men now realized that they had to take responsibility for the changed life situation. However, they were insecure not only as to how they should handle the changed life situation and what kind of emotional and practical support they could give the women, but also how they should handle support to their partner from family, friends, and professionals. Soon after the women came home, they were in need of practical support from community assistants in daily occupations like grooming, dressing, and eating, even though they also received both emotional and practical support from family and friends. To have community assistants at home was a new and strange experience for the men and their wives, and they found it difficult to handle this situation. Since the men had not got or asked for support from professionals earlier, they were now in a situation where they did not have enough knowledge of the consequences of the women's SCI for their performance in daily occupations. Furthermore, the men did not know which kind of support community assistants could give to their wives, and if they could ask for rehabilitation professionals' guidance to better understand how they could help their wives both practically and emotionally in daily occupations.

The changed life situation with practical support from community assistance was difficult to handle for the men, since they and their wives were satisfied with the support and avoided it as much as possible. To meet the women's and their own emotional needs, the men tried to give practical support to the women in self-care and housekeeping, and took on the role as a primary caregiver. Now, for the first time, the men's attitudes towards receiving practical support from professionals in rehabilitation changed. For example, the professionals showed them how they could transfer the women from the wheelchair to the bed. Practical support was something the men willingly gave when they saw how their wives could participate in daily occupations. However, the men could not by themselves support the women in daily occupations as much as they wanted to, because they were working. Instead of practical support from personal or community assistants, a strategy was to have family members and friends at home to provide practical support to the women. Through this practical support from family members and friends, the men could almost handle the changed life situation. One man expressed the unwillingness to have personal assistants in the home like this:

You want to be by yourselves, even if the personal assistants are really good, they came too close to us in everything, you can't get away anywhere in your own home, so together we decided that we did not want to have professionals at home.

To have family members and friends giving practical support to the women became complex when the need for support did not decrease over time. The relationship became tense and the men and their wives found it more important to maintain their friendly relations so they began to end the practical support from friends. At this time, even though they were willing to give practical support to their wives, they found that when the women needed practical support for personal care, even after a while at home, it became a burden for the men. They had to help their wives with personal care and housekeeping, in the morning before they went to work, and again after work in the evening, and during weekends. Although the men found it hard to handle this situation, they continued to give practical support as it was difficult for them to end it. This resulted in a changed life situation for these men with new roles and habits, with little space for their own interests and daily occupations.

"She had tears in her eyes". The men felt that they should support their wives emotionally when they came home after rehabilitation, by listening and talking about their feelings and thoughts. The women were in great need of emotional support, because they felt sad, insecure, and became angry at 
how their life situation had changed. However, the men were insecure about how they could support the women emotionally. One reason was that the men also carried thoughts and feelings of insecurity, fear, and sorrow and therefore found it difficult to give emotional support to the women. One man gave an example of how difficult it was:

If it was a situation where my wife could be all right again within a year or so, but she got that smash in her face at the end of the stay at the hospital: "You will not be able to walk again." I guess it is better to be honest but it was hard for her to take. It was hard for her, and then she came home and was desperate. She came on a stretcher and we met her at home, and she had tears in her eyes. I thought, what had happened, and it was this information. At this moment you had to say something, but what on earth could you say, what could you say?

One strategy to handle the changed life situation emotionally was to give even more practical support in daily occupations and trying to do even better in the practical support. Through this, the men could feel that they supported their wives even if it was not precisely what the women asked for or needed. The men found this situation complex since they knew that it was important for the women to have emotional support at the same time as they did not have the capacity to give it to them. Another strategy was to just listen to the women's thoughts and feelings and avoid getting into discussions or giving any explanations of their own thoughts and feelings. However, the men found that this strategy resulted in a lack of understanding of each other's changed life situation. To find other strategies so they could change this situation, some men said that they wished to have emotional support, for example guidance, from professionals to learn how they could interact with their wives in this changed life situation.

The men found it easier to encourage the women emotionally to resume contact with their earlier social network and to participate in leisure occupations. This was a strategy that the men used since the women came to avoid contacts with, for example, friends and colleagues at work. However, the men were not sure if it was right to encourage their wives to participate in leisure occupations with persons in their social environment because the women had said that they found it complicated to meet some of these people. The emotional support the men gave the women was to stay close to them, deliberately involving them in conversations with others, and through this support they gave the women a sense of belonging. One man described this situation:

It was not easy, she found it hard to meet all these people, she thought it was difficult because she perceived that they did not see her and therefore she found it hard to talk to them. I don't know if we have problems in handling people who have been involved in something like an accident.

The men also encouraged the women through practical support so the women could resume earlier occupations in their daily life like cooking, baking, and gardening, although the men were insecure as to how they should do it. The reason was that they did not know which occupations their wives could perform and in which occupations they needed practical support. The men also felt insecure about how soon after the SCI their wives could perform or participate in occupations again. The men's emotional and practical support for the women's engagement in occupations was also a reason because the men wanted to resume their earlier social network and occupations and it was complicated to leave the women alone. Although the practical support received by the men from professionals soon after their wives returned home was sufficient, the men now found that it was not enough since the women's needs and capacity changed over time. The men therefore experienced that they needed some kind of follow-up support from professionals to discuss how they could handle their changed life situation and give appropriate support to their wife.

"She wanted to do as much as possible by herself". Over time, both the men and their wives realized that, even do it was difficult, it was important to communicate concerning feelings and thoughts. From the men's perspective, the reason was that the men felt insecure about how to support the women and yet be comfortable in their changed life situation. The men thought that through communications they could gain an understanding of how they could support each other in their daily life and through that reduce their insecurity. The men and wives who started to communicate about their mutually changed life situation found they were able to change the support they gave to each other both emotionally and practically.

Through this communication the men and women could, over time, change and develop strategies to solve practical problems in their daily life and adopt new habits and routines that worked for both of them. The men thereby gained a better insight into the women's needs for participation in daily occupa- 
tions and developed practical solutions. These practical solutions included the men taking greater responsibility for activities in the home that demanded physical capacity, and preparing activities for their wives so they could perform occupations in their home by themselves without practical support, such as cooking, washing, and child care. The men also made environmental changes at home, for example, taking away doorsteps and making ramps, so the women could move more freely and participate in occupations in their homes. The men found that these changes were important for both of them and were satisfied to have the competence to make them. The injury changed the performance of daily occupations for both the men and the women but over time they could develop new habits that served both of them through emotional and practical support of each other. Through these strategies both the men and the women could participate in occupations they found interesting and meaningful. One man described it like this:

She wanted to do as much as possible by herself, so I adapted the activities for her, prepared some of them. After that she tried to manage the activity and I did what she couldn't do.

"How you handle it more deeply". The men's changed
life situation led to the ending of some occupations
they had before the women's SCI, for example
travelling and full-time work. However, over time,
the men came to participate in some earlier leisure
occupations without their wives, such as golfing and
skiing. They also developed strategies so they could
participate with their wives in occupations they both
found meaningful, for example sailing and travelling
in a new manner. These strategies were built on
arrangements that led to changed habits and rou-
tines for both of them. Although over time the men
had developed several strategies to handle the
changed life situation, some of the men still wished,
several years after the women's injury, to have
emotional support from professionals to learn how
they could handle this complex and unfolding life
situation in a better way. One man expressed it thus:

I would have liked to have support regarding how you handle it more deeply, how you handle a person when she is in the same situation as my wife.

On the other hand, the men stated, according to their experiences of the changed life situation, that they now, several years after the women's SCI, were against practical support from professionals. One reason was that professionals had questioned their ability to support their wives in daily occupations. Another reason was that they had to wait a long time for changes to the home environment performed by professionals. Some of the men and their wives therefore avoided contact with professionals and instead tried to handle the problems by themselves. The men had, for example, made several modifications at home without support from professionals. However, in situations where they had to accept practical support from professionals, they declared how important it was that these persons were accepted by both themselves and their wives. This process of change over time showed a complexity in adaptation that influenced how the men experienced and acted today, several years after the women's SCI.

In summary, the men's experiences and actions after their wives' SCI showed the complexity of giving and taking practical and emotional support in different life situations during a changed life process over time. The complexity in how the men handled the situation was most obvious in relation to their wives. They wanted to support their wives practically, and found strategies over time to do that; nevertheless they felt insecure as to whether they were giving them the support they needed. Emotionally support was even more difficult to handle for the men since they carried thoughts and feelings of insecurity, fear, and sorrow. However, the men found over time certain strategies to give emotional support, even if they were not sure if these strategies were right. Furthermore, the men stated that they wanted and needed both emotional and practical support from family members and friends soon after the women's SCI at the same time as they experienced that family members and friends could become a burden for them. They also expressed their need for emotional support from healthcare professionals immediately after the SCI to handle their own anxiety, and later on to handle the women's need for emotional support. They also said that practical support from professionals within rehabilitation was important when the women came home after rehabilitation and that they needed but did not get follow-up support when the women's capacity changed over time. However, the men are still in an unfolding process and the following citations illustrate the complexity in how differently two of the men today, several years after the women's injury, experience their changed life situation:

Today we share the occupations in our daily life rather equally ... so I think that I do more or less the same occupations as I did before. It's not a great difference and I don't think that I should 
have done it differently, I don't think that my life would have changed.

I would like to emphasize that it takes a lot from the person that lives with someone that has a spinal cord injury.

\section{Discussion}

This study has described how four male spouses of women with SCI experienced and acted in a process of change when they interacted in giving and taking support with their wives and other persons in their social network. To understand and give some possible explanations for the men's experiences and actions during the process of change the results will be discussed in relation to theories about adaptation and coping.

We found that the men went through a dynamic adaptation process that was still unfolding and built on basic relations with others. This is in agreement with adaptation theories $(35,36)$ that describe personal adaptations as cumulative over time, striving toward an acceptable compromise with the environment. Adaptation is also described as an internal adaptation process built on a construction of positive occupational identity and occupational competence that occurs over time, through and for occupations. Furthermore, major personal changes often require persons to reconstruct both their occupational identity and competence to take their life in a new direction $(14,24)$. How individuals act, think, and feel during this process of change is described in three stages: exploration, competence, and achievement (14).

Put into perspective with our findings these stages give some insights into our results on men's dynamic process of change. In stage one - exploration-persons try out new things and learn about their own capacities, preferences, and values, which require a relatively safe and undemanding environment since the person is still unsure of his own capacity or wishes (14). This description is in accordance with our study, where the men found that it was difficult and complex to handle the new social construction that included giving social support to their wives and taking social support from family members, friends, and rehabilitation professionals. The men's action can be understood as they had not learned how they could handle this changed life situation and the social environment was not safe or undemanding but rather the opposite. Lack of support from professionals can be understood from a biomedical or clinical perspective where the priority is to treat the person's illness (16), and is in accordance with earlier studies $(10-12,22)$. Our results also showed that it was important for the men to feel that they were competent and over time could support their wives. Through new and refined skills, they could minimize support from community assistants to their wives, something both the men and their wives wanted. This is in line with the next stagecompetence - that describes when persons begin to find new ways of doing things that lead to the development of new skills and refinement of old skills. This implies that the men were "seeking" how they could better understand their changed role and begin to establish some degree of balance within their new and often confusing situation, which is in agreement with an earlier study (37). The third stage - achievement - describes when the person integrates a new area of occupational participation into his or her total life (14) and is in accordance with our results. We found that the men over time experienced how important it was to communicate with their wives to get an understanding of each other's needs and negotiate to find meaning in the changed life situation. Through that they could maintain their balance in life as closely as possible to their lifestyle prior to the injury, a result that has been found previously (38). With this adaptation theory we found that we could provide an explanation of the dynamic process the men went through.

To give an explanation for the complexity in our results, we found that theories about coping were appropriate, given that coping can be seen as adaptation under more difficult conditions and as a process that affects the outcome of adaptation $(27,35)$. Through the men's narratives, we found that their new role as caregiver to their wives was complex and included problem-focused coping. The function of problem-focused coping is to change the troubled person-environment relationship by acting on the environment or oneself $(26,39)$. The men used these problem-focused strategies over time, for example, when they decided to take the role as a primary caregiver and took greater responsibility for activities in the home that demanded physical capacity. Furthermore, the men's actions changed over time with their new experiences. We also found, in accordance with earlier studies $(9,19)$, that this problem-focused coping could be a burden for the men, since their own time decreased (with less time for rest and leisure activities) at the same time as it was difficult to end the support they started to give.

Our results also showed that to handle the changed life situation the men were giving more practical than emotional support to their wives. This can be understood in relation to the difficulties of taking a role as caregiver. The role of a caregiver to a disabled partner often means living with an inner struggle or anxiety, sorrow, and helplessness, and 
requires quite a lot of improvisation to internalize $(10,14)$. Ó Brien stated that emotion-focused coping is the way the stressful relationship with the environment is attended to (vigilance or avoidance) or the relational meaning of what is happening, which mitigates the stress even though the conditions of the relationship have not changed, which for example involve denial and distancing (26). Applying his reasoning to our findings, it can be argued that the results showed that the men used both problemfocused coping and emotion-focused coping to control their changed life situation. The men's situation was complex since they experienced over time that these strategies resulted in worsened relations with their wives and this was difficult to change. These strategies can be understood in relation to earlier studies (12) describing how spouses who did not receive emotional support from their social network may have difficulties dealing with their injured partners' emotional problems. Furthermore, spouses of individuals with SCI may suffer higher levels of stress than other close relatives in their caregiving role since they undergo an adjustment process similar to that of their injured partners (20). We found that when the men did not know how they should handle their wives' need for emotional support they used denial and distancing, which can be seen as emotion-focused coping strategies to control the undesirable feelings that result from stressful circumstances $(26,39)$. Furthermore, coping is used whether the process is adaptive or non-adaptive, successful or unsuccessful (26) to handle the complex process of change. The results are in agreement with Lazarus's statement that it is misleading to separate these two functions of coping. Both strategies are interdependent and work together, and both work and affect each other and the outcome of adaptation (39). However, we also agree with Lazarus when he criticizes the coping process for not reaching the complete situation. We therefore found interesting Cutchin's (40) reasoning that it is important to have a more holistic and dynamic understanding of the changes and act between the person and her/his context.

Moreover, it is important to consider that coping processes influence social support through relations to significant others and are influenced by them as well, and also that not all social relationships are supportive but can become a stressor $(19,26)$. The men in this study, in agreement with an earlier study (12), asked for support from family members and friends instead of professionals in rehabilitation soon after their wives' SCI. However, over time the men realized that support from family members and friends could become a stressor that was complex and difficult to handle since it affected their relationships. Lack of correct support from professionals also became a stressor for the men and influenced how they coped with their changed life situation. Receiving support from their wives, family members, and friends as well as professionals can be described as a coping strategy. Through these strategies, the men could change the situation, and their emotional reaction to the situation, indicating a mutual relationship between coping and social support (28). Our results are also in line with King et al. (8) who described that practical and emotional support from professionals could facilitate better understanding, feelings of competence, and strategies for acting in a changed life situation. However, our results also showed that lack of emotional support soon after the SCI and lack of practical support some time after the SCI could lead to feelings of anger and avoidance of professional support. Also, Brereton and Nolan (37) stated that it is important for rehabilitation professionals to prepare and support spouses over time through their partners. This implies that it is of value to see social support as a process rather than a resource or outcome in order to gain a better understanding of how persons experience support and how that affects future directions in life. This is of great importance for rehabilitation professionals and in agreement with King et al. (8) we found that rehabilitation professionals have to consider the importance of both practical and emotional support and how relationships grow stronger or weaker through expectations around support over time.

\section{Methodological considerations}

To gain access to the process of change, we used a narrative method since narratives are a person's way of interpreting and making meaning from experiences over time (29). The results showed that a narrative method was appropriate to understand the spouses' experiences over time. A strength of this narrative method is that the study does not simply produce a reproduction of data, instead it provides a dynamic framework in which the range of disconnected data elements are made to cohere in an interesting and explanatory way (30). However, it is important to be aware that recollection of past events is selective and produced from the present perspective of the participants, and the meaning of the event in the present may differ from the time of the original experience (30). It is also important to point out that one of the participants met his wife some years after her injury and could not contribute to the whole story. However, the man matched the inclusion criteria and his narrative was important for the results. To enhance trustworthiness and improve 
credibility, the first and last authors had a constant dialogue during the analysis process (33) with the second author who is experienced in narrative analysis, as well as discussions with the third author who is an experienced rehabilitation medicine specialist.

\section{Conclusions}

From our results, we conclude that, after their wives' SCI, the men went through a process of change which was dynamic, complex, and is still unfolding. The men were confronting changed social constructions through giving and taking social support to their wives and other persons in their social network. They explained how complex it was to act in the way they thought was right and their actions also had to change over time. Through this action-taking they gained new experiences and found new strategies which enabled them to handle this process of change in their daily life. Through theories concerning adaptation and coping, we could give some explanations of the men's experiences and actions and of how they found strategies to handle their daily lives. Furthermore, we found that it is important for rehabilitation professionals to see social support as a process of change. The results indicate that rehabilitation professionals and others in the healthcare system need to develop interventions in an ongoing but different way than has been viewed traditionally, for example through the use of narratives from spouses to understand the dynamic and complex process of change they went through after their partners had a sudden injury or disease.

\section{Acknowledgements}

The authors would like to give special thanks to the men who openly shared their experiences. Financial support was provided by Luleå University of Technology, Skåne County Council's Research and Development Foundation and the Swedish Association of Persons with Neurological Disabilities.

\section{References}

1. Isaksson G, Josephsson S, Lexell J, Skär L. To regain participation in occupations through human encounters: Narratives from women with spinal cord injury. Disabil Rehabil 2007:1679-88.

2. Fougeyrollas P, Noreau L, Bergeron H, Cloutier R, Dion S-A, St-Michel G. Social consequences of long term impairments and disabilities: Conceptual approach and assessment of handicap. Int J Rehabil Res. 1998;21:127-41.

3. Krause JS, Kemp B, Coker J. Depression after spinal cord injury: Relation to gender, ethnicity, aging, and socioeconomic indicators. Arch Phys Med Rehabil. 2000;81:1099109.
4. Li L, Moore D. Acceptance of disability and its correlates. J Soc Psych. 1998;138:13-25.

5. Tzonichaki I, Kleftaras G. Paraplegia from spinal cord injury: Self-esteem, loneliness, and life satisfaction. OTJR: Occupation. Participation and Health. 2002;22:96-103.

6. Isaksson G, Lexell J, Skär L. Social support provides motivation and ability to participate in occupation. OTJR: Occupation. Participation and Health. 2007;27:23-30.

7. Isaksson G, Skär L, Lexell J. Women's perceptions of changes in the social network after a spinal cord injury. Disabil Rehabil. 2005;27:1013-21.

8. King G, Willoughby C, Specht JA, Brown E. Social support processes and the adaptation of individuals with chronic disabilities. Qualitative Health Res. 2006;16:902-25.

9. Söderberg S, Strand M, Haapala M, Lundman B. Living with a woman with fibromyalgia from the perspective of the husband. J Adv Nurs. 2003;42:143-50.

10. Lindholm L, Rehnsfeldt A, Arman M, Hamrin E. Significant others' experience of suffering when living with women with breast cancer. Scand J Car Sci. 2002;16:248-55.

11. Paterson B, Kieloch B, Gmiterek J. They never told us anything': Postdischarge instruction for families of persons with brain injuries. Rehabil Nurs. 2001;26:48-53.

12. Smith JE, Smith DL. No map, no guide. J Case Management. 2000;2:27-33.

13. Holtz A, Levi R. Ryggmärgsskador (Spinal Cord Injury). Lund: Studentlitteratur; 2006 (in Swedish).

14. Kielhofner G. Model of human occupation. 3rd ed. Philadelphia: Lippincott Williams \& Wilkins; 2002.

15. Lawlor MC, Mattingly CF. The complexities embedded in family-centered care. Am J Occup Ther. 1998;52:259-67.

16. Mattingly CF, Lawlor MC. Disability experience from a family perspective. In: Blesedell Crepeau E, Cohn ES, Boyt Shell BA, editors. Willard \& Spackman's occupational therapy. Philadelphia: Lippincott Williams \& Wilkins; 2003.

17. McColl MA, Lei H, Skinner H. Structural relationships between social support and coping. Soc Sci Med. 1995;41: 395-407.

18. Holicky R, Charlifue S. Ageing with spinal cord injury: The impact of spousal support. Disabil Rehabil. 1999;21:250-7.

19. De Ridder D, Schreurs K. Coping, social support and chronic disease: A research agenda. Phych Health Med. 1996;1:7182 .

20. Chan RC. Stress and coping in spouses of persons with spinal cord injuries. Clin Rehab. 2000;14:137-44.

21. O'Brien MT. Multiple sclerosis: Stressors and coping strategies in spousal caregivers. J Comm Health Nurs. 1993;10: 123-35.

22. Jumisko E. Being forced to live a different everyday life: The experiences of people with traumatic brain injury and those of their close relatives [Licentiate]. Luleå: Luleå University of Technology; 2005.

23. Kielhofner G, Forsyth K. Commentary on Cutchin's using Deweyan philosophy to rename and reframe adaptation-toenvironment. Am J Occup Ther. 2004;58:313-4.

24. Schultz S, Schkade JK. Theories derived from occupational behaviour perspectives, section 3. In: Blesedell Crepeau E, Cohn ES, Boyt Shell BA, editors. Willard and Spackman's occupational therapy. Philadelphia: Lippincott Williams \& Wilkins; 2003.

25. Meleis AI, Sawyer LM, Im E-O, Hilfinger Messias DK, Schumacher K. Experiencing transitions: An emerging middle-range theory. Adv Nurs Sci. 2000;23:12-28.

26. Lazarus RS. Coping theory and research: Past, present, and future. Psychosom Med. 1993;55:234-47.

27. Reed KL. An annotated history of the concepts used in occupational therapy. In: Christiansen $\mathrm{CH}$, Baum C, Bass- 
Haugen J, editors. Occupational therapy performance, participation, and well-being. Thorofare, NJ: SLACK Incorporated; 2005

28. Thoits PA. Social support as coping assistance. J Consult Clin Psych. 1986;54:416-23.

29. Josephsson S, Asaba E, Jonsson H, Alsaker S. Creativity and order in communication: Implications from philosophy to narrative research concerning human occupation. Scand J Occup Ther. 2006;13:86-93.

30. Polkinghorne DE. Narrative configuration in qualitative analysis. Int J Qual Stud Education. 1995;8:8-25.

31. Ödman P-J. Tolkning förståelse vetande, hermeneutik i teori och praktik [Interpretation, understanding and knowing, hermenutics in theory and practice]. Stockholm: Norstedts förlag; 1994 (in Swedish).

32. Patton MQ. Qualitative research and evaluation methods. London: Sage Publications; 2002.

33. Lincoln YS, Guba EG. Naturalistic inquiry. London: Sage Publications; 1985.
34. Spence DP. Narrative smoothing and clinical wisdom. In: Sarbin TR, editor. Narrative psychology: The storied nature of human conduct. New York: Praeger; 1986. p. 211-32.

35. Thorén Jönsson A-L, Möller A, Grimby G. Managing occupations in everyday life to achieve adaptation. Am J Occup Ther. 1999;53:353-62.

36. Mandelbaum DG. The study of life history: Gandhi. Current Anthropol. 1973;14:177-206.

37. Brereton L, Nolan M. Seeking': A key activity for new family carers of stroke survivors. J Clin Nurs. 2002;11:22-31.

38. Eriksson M, Svedlund M. The intruder': Spouses'narratives about life with a chronically ill partner. J Clin Nurs. 2006;15: 324-33.

39. Lazarus RS. Toward better research on stress and coping. Am Psych. 2000;55:665-73.

40. Cutchin MP. Using Deweyan philosophy to rename and reframe adaptation-to-environment. Am J Occup Ther. 2004; $58: 303-12$. 